\title{
Educação: um direito prioritário
}

\begin{abstract}
Marília Costa Dias é pedagoga pela Universidade Federal do Rio Grande do Sul e mestra em Educação pela Universidade de São Paulo. É professora do Curso de Pedagogia e coordenadora do curso de especialização em Educação Inclusiva do Instituto Superior de Educação Vera Cruz. Além disso, é gerente técnica na APAE de São Paulo.
\end{abstract}

Contato: mariliac@ajato.com.br

\section{Resumo}

0 tema educação para todos vem sendo discutido nas duas últimas décadas com muita intensidade, e são muitos os esforços, tanto no Brasil como no mundo, no sentido de garantir o direito de todos a um processo de escolarização com qualidade. Este artigo é resultado de um estudo bibliográfico sobre o direito à educação, como direito humano prioritário, tendo como foco o direito à educação para as pessoas com deficiência. Primeiramente são apresentadas algumas contribuições sobre os direitos humanos como base da discussão sobre o direito à educação. Em seguida, o texto aborda como esse direito é expresso na legislação brasileira e nos documentos internacionais e põe em discussão alguns aspectos relacionados à exigibilidade do mesmo. Palavras-chave: direito à educação; deficiência; educação inclusiva.

\section{Abstract}

The theme of education for all has been discussed in the last two decades with intensity, and there are many efforts, both in Brazil and worldwide, to ensure everyone's right to a quality education process. This article is the result of a bibliographical study on the right to education as a critical human right, focusing on the right to education for people with disabilities. First, we present some contributions on human rights as the basis for discussion about the right to education. Then the text discusses how this right is expressed in Brazilian legislation and international documents, and addresses some aspects related to guarantee this right.

Keywords: right to education, disability, inclusive education. 
A educação é considerada um direito humano fundamental desde 1948, quando foi reconhecida como tal na Declaração Universal dos Direitos Humanos (art. 26). Entender o significado do direito à educação, nos dias atuais, requer compreender como a educação se constituiu como direito ao longo do tempo. E, para isso, cabe uma reflexão sobre como surgiu a ideia de que existem direitos humanos, ou "direitos do homem".

Segundo Dallari (2004), uma das primeiras referências históricas sobre direitos da pessoa humana encontra-se na Grécia Antiga, na obra de teatro Antígona, de Sófocles. Nesta, o irmão de Antígona é preso e condenado à morte como traidor. 0 rei de Tebas determina que seu corpo não seja enterrado, devendo ficar exposto até apodrecer para servir de exemplo a outros. Antígona desafia o rei ao dar enterro ao irmão, valendo-se de um direito universal, muito mais antigo que as leis daquele reinado, que é o direito à dignidade. Para o autor, Antígona desafia a lei instituída pelos homens por considerar mais importante cumprir as leis não escritas, ou seja, as leis divinas, que teriam um caráter universal.

De acordo com Comparato (2001), a ideia de que existe igualdade entre todos os homens, uma das premissas dos direitos humanos, remonta a muitos anos antes de Cristo, quando grandes pensadores, como Zaratustra, na Pérsia; Buda, na Índia; Lao-Tsé e Confúcio, na China; Pitágoras, na Grécia; e Isaías, em Israel, formularam princípios fundamentais para a vida humana.

0 mesmo autor enfatiza que diferentes religiões reconhecem os seres humanos como iguais perante o seu deus, e por meio das leis sagradas, reveladas pelos profetas, anunciam como alcançar a verdade e a justiça. Para Comparato (2001), a tentativa de regular as relações humanas por meio de leis divinas é muito antiga. Os Dez Mandamentos e a pregação de Jesus representam, para o mundo cristão, uma tentativa de "educar" a natureza humana; a mesma tentativa é observada em passagens do Torah, no Judaísmo, ou do Alcorão, no Islamismo. Mas, efetivamente, do ponto de vista das religiões, a igualdade só existe no plano espiritual, pois durante séculos elas conviveram e aceitaram como legítimas a escravidão, a inferioridade das mulheres em relação ao homem e até mesmo a colonização de outros povos. 
Para Comparato (2001), a consciência sobre direitos humanos surge com as primeiras instituições democráticas, em Atenas, e com a fundação da República Romana, onde havia o reconhecimento do direito de participar ativamente da vida da cidade e tomar decisões políticas, embora esse direito se restringisse a um número pequeno de homens que participavam da vida pública na cidade. A esse respeito, Benevides (2004) esclarece que "estavam excluídos da cidadania as mulheres, os estrangeiros, os comerciantes, os artesãos (estes dois grupos por não terem, supostamente, tempo livre para as tarefas públicas) e, evidentemente, os escravos" (p. 44).

Posteriormente, nos séculos XVII e XVIII, começa na Europa um movimento revolucionário, por causa das injustiças e arbitrariedades da concentração de poder nos reis e nobres, que culmina com a Revolução Francesa, em 1789, e com a Declaração dos Direitos do Homem e do Cidadão, do mesmo ano, afirmando a liberdade e a igualdade como direitos de todos. Esse movimento desencadearia, a partir da segunda metade do século XIX, avanços em relação ao direito humanitário, à luta contra a escravidão e aos direitos do trabalhador assalariado (Comparato, 2001). Esse autor também destaca a Declaração de Independência dos Estados Unidos, de 1776, como um dos movimentos precursores dos direitos humanos, ao reconhecer que os homens são igualmente livres e independentes e detentores de direitos inatos.

Em 1945, ao fim da Segunda Guerra Mundial, é criada a Organização das Nações Unidas (ONU), que em 1948 afirmaria historicamente os direitos humanos, por meio da já mencionada Declaração Universal dos Direitos Humanos. Como aponta Benevides (2004), essa declaração proclama um sistema de valores de caráter universal, pois diz respeito à natureza humana, a todos os homens, cidadãos do mundo. São considerados direitos naturais porque não precisam ser explicitados legalmente, e estão acima de qualquer lei. E são considerados como direitos positivos na medida em que podem ser exigidos ou garantidos pela comunidade internacional.

Todo homem tem valor pelo simples fato de ser homem, independentemente de suas qualidades ou de sua conduta, pois a dignidade da pessoa humana, na condição de valor fundamental, atrai o conteúdo de todos os outros direitos, que devem ser reconhecidos e protegidos. Nesse raciocínio, sempre que os direitos fundamentais não forem reconhecidos, a dignidade da pessoa humana estará sendo negada (Ribeiro, 2007). 
0 direito à educação signnifica direito a um processo de desenvolvimento que respeite e favoreça a realização de todos os outros direitos. Nesse sentido, vale destacar que o direito à educação é "um dos requisitos para que os indivíduos tenham acesso ao conjunto de bens e serviços disponíveis na sociedade, constituindo-se em condição necessária para se usufruírem outros direitos constitutivos do estatuto de cidadania" (Oliveira, 2007, p. 15).

Tavares (2006, p. 63) ressalta que "o direito à educação é indispensável para a vida em sua plenitude", pois considera que a educação é um dos direitos essenciais que garantem o desenvolvimento da personalidade humana e em sua ausência o homem perde a razão de ser, de existir. Para Pontes (2007), somente por meio da educação poderemos atingir o ápice de respeito ao princípio da dignidade da pessoa humana, pois, com ela, serão formadas pessoas conscientes de seus direitos e de seu papel na sociedade (p. 146).

Como destaca Monteiro (2003), o direito à educação é um direito prioritário, pois o ser humano tem real necessidade e capacidade de educação e somos esculpidos pelo processo educativo: "O direito à educação é um direito prioritário, mas não é um direito qualquer: é direito a uma educação com qualidade de direito de homem" (p. 764). Ou seja, refere-se a uma educação que garanta os conteúdos essenciais para uma vida com dignidade.

Monteiro (2003) chama a atenção para um aspecto de extrema relevância: que "a educação é necessária, mas nem toda educação é legítima" (p. 786). Esse autor ressalta a significação ética do direito à educação ao afirmar que "é o mais fundamental dos direitos para uma vida humana, tanto para as gerações presentes como para as gerações futuras" (p. 786). Para o autor, tal direito implica "repensar a educação, transfigurar a escola e recriar a identidade dos profissionais de educação" (p. 764), se quisermos de fato romper com o "círculo vicioso de autorreprodução histórica e psicológica dos males seculares da educação" (Monteiro, 2003, p. 787).

\section{A educação como direito humano}

A década de 1990 serviria de "marco para o delineamento e a execução de políticas educativas no mundo inteiro, principalmente em educação básica" (Torres, 2001, p. 8). 0 contexto da época era de profundas e rápidas transformações, com contradições e incertezas profundas em função do grande desenvolvimento tecnológico e do crescente processo de globalização. Segundo 
esse autor, as estatísticas desse período apontavam mais de 100 milhões de crianças sem acesso à escola e mais de 960 milhões de adultos analfabetos no mundo, sendo dois terços deles mulheres.

Reconhecendo a gravidade dessa situação, quatro agências internacionais - Organização das Nações Unidas para a Educação, a Ciência e a Cultura (Unesco), Fundo da Nações Unidas para a Infância (Unicef), Programa das Nações Unidas para o Desenvolvimento (PNUD) e o Banco Mundial (BM) - promoveram a Conferência Mundial Educação para Todos, em 1990, em Jomtien, na Tailândia, que estabeleceu metas mundiais para a educação, chamando a atenção para a importância e prioridade da educação, principalmente da básica (Torres, 2001).

Em 1993 a Unesco criou a Comissão Internacional sobre Educação para o Século XXI, com a finalidade de estudar e pensar sobre os desafios para a educação no novo milênio. Essa comissão, presidida por Jacques Delors, reconhece a educação como direito fundamental da pessoa humana, que deve ser desenvolvida ao longo da vida e como responsabilidade de toda a sociedade (Abenhaim, 2005).

De acordo com essa autora, no início da década de 90 havia um movimento mundial em favor das pessoas com necessidades educacionais especiais, que "propunha a inclusão social dessas pessoas e não estava satisfeito com a tentativa de integração social que vinha acontecendo nas escolas regulares, quando elas eram colocadas em classes especiais" (Abenhaim, 2005, p. 42). Segundo a autora, no contexto da discussão sobre Educação para Todos, esse movimento percebeu a necessidade de explicitar o lugar das pessoas com necessidades educacionais especiais e deu origem a outro marco importante na discussão sobre o papel da educação, que foi a Conferência Mundial sobre Necessidades Educativas Especiais: Acesso e Qualidade, que ocorreu em 1994 na cidade de Salamanca, Espanha, e que resultou na Declaração de Salamanca (1994). Essa Declaração propõe um novo modelo de escola na perspectiva da educação inclusiva, que garanta a aprendizagem de todos os alunos.

Dez anos depois da Conferência Mundial sobre a Educação para Todos, em 2000, o cumprimento de suas metas foi avaliada pela Cúpula Mundial de Educação, em Dacar, e foram constatados progressos significativos em muitos países. No entanto, considerou-se inaceitável que, naquele ano, 113 milhões de crianças continuassem sem acesso ao ensino primário e 800 milhões de adultos permanecessem analfabetos, entre outros 
resultados igualmente assustadores (Abenhaim, 2005). Segundo a autora, essa avaliação deu origem à proposta de elaboração dos Planos Nacionais de Educação por parte dos governos, com a participação da sociedade civil, para melhorar a qualidade e a eficiência da educação.

No âmbito internacional, outro importante marco de referência na afirmação dos direitos humanos foi a Convenção dos Direitos das Pessoas com Deficiência, elaborada em 2006 por representantes de vários países, muitos com deficiência, sendo "construída a partir da óptica de que as próprias pessoas com deficiência são as que sabem o que é melhor para elas e por isso devem ser ouvidas em todas as ações que as envolvam" (Brasil, 2008a, p. 16). Essa convenção foi assinada pelo Brasil (e mais 196 países) em março de 2007, aprovada em 9 de julho de 2008 pelo Decreto Legislativo n ${ }^{\circ} 186$ e promulgada em 25 de agosto de 2009 pelo Decreto Presidencial n 6.949. Ela afirma que

\footnotetext{
os Estados Partes reconhecem o direito das pessoas com deficiência à educação. Para efetivar esse direito sem discriminação e com base na igualdade de oportunidades, os Estados Partes assegurarão sistema educacional inclusivo em todos os níveis, bem como o aprendizado ao longo de toda a vida (Nações Unidas, 2006, art. 24, apud Brasil, 2008a).
}

Portanto, na última década, as discussões sobre educação, em âmbito internacional, expressam o direito das pessoas com deficiência de frequentar a escola comum, tendo como pressuposto que os sistemas de ensino devem ser inclusivos. Isso não significa, no entanto, que esse direito esteja assegurado a todas as pessoas com deficiência.

Em 2009, durante a Conferência Mundial de Educação Inclusiva, que ocorreu em Salamanca, na Espanha, foi divulgado o informe Mejor Educación para Todos: cuando se nos incluya también, no qual pessoas com deficiência intelectual, suas famílias, seus professores e outros partidários, de mais de 75 países, relatam suas experiências sobre Educação para Todos, deficiência e educação inclusiva.

Nesse estudo, constatou-se que a maioria dos países adotaram compromissos com a educação inclusiva, mas os entrevistados dizem que, até nos países com boa legislação e políticas adequadas, a inclusão escolar ainda não é uma realidade:

- Na América Central, quase todos os países já adotaram leis e políticas que afirmam a educação inclusiva, mas a 
prática está muito longe das metas da Educação para Todos estabelecidas no Fórum Mundial sobre Educação, em Dacar, Senegal, em 2000.

- Canadá, Nova Zelândia, Estados Unidos e alguns países europeus investem em leis que protegem os direitos humanos; no entanto, na prática, a implementação das leis ainda não tem um enfoque baseado nos direitos humanos.

- No continente africano poucos países adotaram declarações ou políticas referentes às pessoas com deficiência.

- Em alguns lugares, a legislação e a política se referem à inclusão de grupos marginalizados, porém não levam em conta as crianças com deficiência.

- Em outros casos, a legislação que se centra nas necessidades dos alunos com deficiência tem como resultado o desenvolvimento de práticas de segregação ou de isolamento (Inclusion International, 2009).

Esse informe chama a atenção para o fato de que a maioria dos 75 países assume o compromisso do direito dos alunos com deficiência frequentarem a escola regular, mas reconhece que os apoios a eles ainda são inadequados e ineficientes. Muitas das famílias e alunos entrevistados relataram histórias de rejeição por parte de administradores, diretores e professores das escolas. Segundo o referido documento,

\footnotetext{
isto é comum em países em desenvolvimento, mas também é frequente em países ricos, onde prevalecem os programas segregados. De todos os fatores que se têm identificado como causas da vulnerabilidade das crianças à exclusão (ser menina, aids, pobreza, etnia etc.) a deficiência segue sendo a principal razão para a exclusão (Inclusion International, 2009, p. 63, tradução da autora).
}

\section{0 direito à educação nas constituições brasileiras}

No contexto brasileiro, de acordo com Tavares (2006), o direito à educação foi mencionado já na primeira Constituição Federal (1824), no art. 179, XXXII, onde se lê que "a instrução primária é gratuita a todos os cidadãos" (Brasil, 1824), embora nem todos fossem considerados cidadãos, como era o caso dos índios, negros e mulheres (Tavares, 2006). Somente em 1934, na Constituição, que durou apenas três anos, foi dedicado um capítulo inteiro à 
educação. Segundo o mesmo autor, essa Constituição foi um marco na legislação nacional, pois instituiu a educação como direito de todos, a qual deveria ser gratuita e obrigatória no ensino primário (Brasil, 1934, arts. 149 e 150).

Nas Constituições de 1937, 1946 e 1967 não há avanços significativos em relação ao direito à educação. É somente na Constituição Federal de 1988, no art. 205, que fica instituída a educação como "direito de todos e dever do Estado e da família" (Brasil, 1988), a qual deve ser "promovida e incentivada com a colaboração da sociedade, visando ao pleno desenvolvimento da pessoa, seu preparo para o exercício da cidadania e sua qualificação para o trabalho" (Brasil, 1988). A Constituição de 1988 também definiu o direito à "igualdade de condições para acesso e permanência na escola" (art. 206); "ensino fundamental, obrigatório e gratuito, inclusive para os que a ele não tiveram acesso na idade própria" (art. 208, inciso I); e também o "atendimento educacional especializado, preferencialmente, na rede regular de ensino" (art. 208, inciso III), o que depois foi reafirmado, em 1996, pela Lei de Diretrizes e Bases da Educação Nacional (LDB) - Lei no 9.394 (Brasil, 1996). Portanto, no Brasil, há mais de 20 anos a educação escolar, além de ser um direito de todos, é obrigatória e gratuita no ensino fundamental.

Em 2009, com a promulgação da Emenda Constitucional $n^{0} 59$, que dá nova redação aos incisos I e VII do art. 208 da CF/88, a educação básica passou a ser obrigatória e gratuita dos 4 (quatro) aos 17 (dezessete) anos de idade. Isso significa uma expressiva ampliação da obrigatoriedade do ensino, considerando que a educação escolar do ensino médio e da educação infantil eram facultativas, até então.

Isso não significa, no entanto, que o direito à educação esteja efetivado para todos. Temos, em nosso país, um quadro de extrema desigualdade social e um forte processo de exclusão ao longo dos anos de escolaridade, como revelam os indicadores sociais apresentados pelo Instituto Brasileiro de Geografia e Estatística (IBGE):

Embora entre as crianças e adolescentes de 7 a 14 anos de idade, faixa etária correspondente ao ensino fundamental, o ensino esteja praticamente universalizado $(97,6 \%)$, os resultados da pesquisa mostram que este alto índice de frequência à escola nem sempre se traduz em qualidade do aprendizado. Entre os 28,3 milhões de crianças de 7 a 14 anos, que pela idade já teriam passado pelo processo de alfabetização, foram encontradas 2,4 milhões $(8,4 \%)$ que não sabem ler e escrever. 
Isto não significa que estas crianças não estejam na escola: 2,1 milhões delas, ou seja, $87,2 \%$, das que não sabiam ler e escrever, frequentavam estabelecimento de ensino. Deste grupo de 2,1 milhões, 1,2 milhão vivia no Nordeste do país. (Brasil, 2009a).

\section{0 direito à educação das pessoas com deficiência}

Em relação à educação das pessoas com deficiência, foi em 1961, na primeira Lei de Diretrizes e Bases da Educação Nacional (Lei n ${ }^{\circ} 4.024 / 61$ ), que pela primeira vez aparece a "educação de excepcionais como um título $(\mathrm{X})$ com dois artigos (88 e 89), destacado da educação de grau primário (título VI). Assim legalmente se afirma a peculiaridade dessa educação" (Jannuzzi, 2006, p. 68).

Como explica Mendes (2006), foi em 1970, com a expansão do sistema educacional público para garantir o acesso à escola para a população em geral, que surgiu uma preocupação oficial com os alunos que não se encaixavam nos padrões estabelecidos para o ensino regular. Assim, foi institucionalizada a educação especial no sistema educacional público brasileiro, com a criação do Centro Nacional de Educação Especial (Cenesp), em 1973, órgão do Ministério da Educação responsável pelas primeiras providências no sentido de definir diretrizes para o atendimento específico da educação especial, seguindo uma linha preventiva e corretiva, conforme orientação da própria portaria que o criou, que atribuía um sentido clínico e/ou terapêutico à educação especial (Mazzotta, 2005). A partir dessas diretrizes foram implantadas diversas classes e escolas especiais na rede pública de ensino, e implementados projetos de formação de recursos humanos especializados (Glat; Blanco, 2007).

Em 2001, o MEC publicou as Diretrizes Nacionais para a Educação Especial na Educação Básica, por meio da Resolução CNE/CEB $n^{\circ} 2 / 2001$, na qual afirma no seu art. $2^{\circ}$ que

\footnotetext{
os sistemas de ensino devem matricular todos os alunos, cabendo às escolas organizar-se para o atendimento aos educandos com necessidades educacionais especiais, assegurando as condições necessárias para uma educação de qualidade para todos (BRASIL, 2001, grifo nosso).
}

No entanto, por essa mesma resolução, a educação especial pode substituir a escolaridade em classe comum, embora somente em alguns casos, de acordo com o art. $3^{\circ}$ : 


\begin{abstract}
Por educação especial, modalidade da educação escolar, entende-se um processo educacional definido por uma proposta pedagógica que assegure recursos e serviços educacionais especiais, organizados institucionalmente para apoiar, complementar, suplementar e, em alguns casos, substituir os serviços educacionais comuns, de modo a garantir a educação escolar e promover o desenvolvimento das potencialidades dos educandos que apresentam necessidades educacionais especiais, em todas as etapas e modalidades da educação básica (Brasil, 2001, grifo nosso).
\end{abstract}

Esse entendimento é distinto de outros documentos, como a cartilha $O$ acesso de alunos com deficiência às escolas e classes comuns da rede regular, publicada em 2004 pelo Ministério Público Federal (MPF), com apoio do MEC. Nesse documento afirma-se que o atendimento educacional especializado, previsto pela Constituição Federal de 1988, "funciona nos moldes similares a outros cursos que complementam os conhecimentos adquiridos nos níveis de ensino básico e superior, como é o caso dos cursos de línguas, artes, informática e outros" (Brasil, 2004, p. 8).

Nessa perspectiva, a LDB/96, em seu art. 58, define a educação especial como "modalidade de educação escolar, oferecida preferencialmente na rede regular de ensino, para educandos portadores de necessidades especiais" (Brasil, 1996). Para Pontes (2007), sendo a educação especial uma modalidade educacional, que perpassa todos os níveis escolares, não pode funcionar como substitutivo da educação escolar. Portanto, considera que "optando os pais ou responsáveis apenas pela educação especial (ou atendimento educacional especializado), não estarão garantindo o direito fundamental à educação" (Pontes, 2007, p. 144).

0 mesmo art. 58 da LDB/96 estabelece que "o atendimento educacional será feito em classes, escolas ou serviços especializados, sempre que, em função das condições específicas dos alunos, não for possível a sua integração nas classes comuns de ensino regular" (Brasil, 1996, art. 58, $\S 2^{\circ}$ ), entretanto, para Pontes (2007),

\footnotetext{
[...] isso não significa que ao aluno "que não conseguiu se integrar" será oferecido unicamente o atendimento educacional especializado. Primeiramente porque este é apenas um suporte, um apoio, um complemento e não a própria escolarização, significando esta possibilidade na negação do acesso ao direito à educação. [...] Não há uma autorização da LDB para que a escolarização seja oferecida em ambiente segregado [...]. (p. 151).
} 
Em janeiro de 2008, o MEC divulgou a Política Nacional de Educação Especial na Perspectiva da Educação Inclusiva (PNEE/2008), a qual reitera que

\begin{abstract}
[...] a educação especial é uma modalidade de ensino que perpassa todos os níveis, etapas e modalidades, realiza o atendimento educacional especializado, disponibiliza os serviços e recursos próprios desse atendimento e orienta os alunos e seus professores quanto a sua utilização nas turmas comuns do ensino regular. [...] Em todas as etapas e modalidades da educação básica, o atendimento educacional especializado é organizado para apoiar o desenvolvimento dos alunos, constituindo oferta obrigatória dos sistemas de ensino e deve ser realizado no turno inverso ao da classe comum, na própria escola ou centro especializado que realize esse serviço educacional. (Brasil, 2008b).
\end{abstract}

A Convenção sobre os Direitos das Pessoas com Deficiência (2006) é um importante instrumento legal para defender e garantir os direitos das pessoas com deficiência em todas as áreas da vida: saúde, educação, trabalho, vida familiar, esportes, vida cultural, pois todos os seus artigos assumiram status constitucional, a partir do momento em que foi ratificada e promulgada pelo governo brasileiro. Em seu texto, não é mais utilizado o termo 'educação especial', e aparece com ênfase o direito das pessoas com deficiência à educação, ao longo da vida, assegurandoIhes as adaptações e os apoios necessários para maximizar o desenvolvimento acadêmico e social.

No entendimento de Fávero (2007), nessa Convenção "não há cumprimento do direito à educação fora de um sistema educacional inclusivo em todos os níveis" (p. 97). Entretanto, a autora explica que isso não significa

\section{[... o fim do ensino especializado e segregado, exclusivo para alunos com necessidades educacionais especiais, mas é mais um sinal de que o ensino especializado deve cumprir a obrigação de se reestruturar para que, definitivamente, não seja mais substitutivo do direito de acesso ao ensino comum (p. 90).}

Nesse sentido, é importante chamar a atenção para as contribuições de Araújo e Neme (2009), ao afirmarem que "o primeiro efeito da nova Convenção foi ingressar como cláusula pétrea', impedindo qualquer modificação futura" (p. 733). E ainda que "como norma posterior (e norma posterior de hierarquia superior), ela revoga o direito, até então existente, que for contrário a ela" (p. 734). Por isso, a Convenção é considerada pelos
1. Cláusula pétrea significa artigo ou disposição legal que deve ser cumprida obrigatoriamente, que não permite renúncia ou inaplicabilidade, por estar petrificada, dura, imóvel, por ser inquebrável e intocável. É lei ou norma que se cumpre sem qualquer discussão quanto a sua interpretação de viabilidade - fática ou de direito -, por ser e estar taxativamente blindada na ordem constitucional, não se modifica, não se revoga ou não se reforma. É, portanto, superior hierarquicamente falando, quanto à validade e soberania legal, e faz parte da base e do sistema jurídico adotado e assegurado (Maia Neto, 2010). 
autores como um "excelente instrumento para a proteção dos direitos das pessoas com deficiência que impõe deveres, cobra prestações positivas dos Estados e determina conceitos que devem ser seguidos pelos países signatários" (p. 733).

Em setembro de 2008, foi publicado o Decreto $n^{\circ} 6.571$, no qual "considera-se atendimento educacional especializado o conjunto de atividades, recursos de acessibilidade e pedagógicos organizados institucionalmente, prestado de forma complementar ou suplementar à formação dos alunos no ensino regular" (Brasil, 2008c, art. 10). Como é possível observar, esse é outro documento oficial que reafirma a educação especial apenas como complementar e suplementar. Além disso, esse decreto institui,

\section{[...] a partir de $1^{\circ}$ de janeiro de 2010, para efeito da distribuição dos recursos do Fundeb, o cômputo das matrículas dos alunos da educação regular da rede pública que recebem atendimento educacional especializado, sem prejuízo do cômputo dessas matrículas na educação básica regular (Brasil, 2008c, art. 9).}

Em 2009, foi homologado o Parecer nº 13 do Conselho Nacional de Educação/Câmara de Educação Básica, que regulamenta o Decreto $n^{\circ} 6.571$ (Brasil, 2008c) e a Resolução CNE/CEB 4/2009, definindo as diretrizes operacionais para o atendimento educacional especializado na Educação Básica, modalidade Educação Especial. Em seu texto fica explicitado que

\footnotetext{
a concepção da Educação Especial nesta perspectiva da educação inclusiva busca superar a visão do caráter substitutivo da Educação Especial ao ensino comum, bem como a organização de espaços educacionais separados para alunos com deficiência. Essa compreensão orienta que a oferta do AEE será planejada para ser realizada em turno inverso ao da escolarização, contribuindo efetivamente para garantir o acesso dos alunos à educação comum e disponibilizando os serviços e apoios nas classes comuns da rede regular de ensino (Brasil, 2009b).
}

No entendimento de Araújo e Neme (2009), "como a Convenção surge como um título equivalente à emenda constitucional, ela provocará uma modificação no sistema do direito interno" (p. 733). Nesse sentido, vale refletir se o caráter substitutivo da educação especial não restringe o direito à educação, pois de acordo com a Convenção (art. 24), para a realização desse direito, os Estados Partes devem assegurar que 
as pessoas com deficiência não sejam excluídas do sistema educacional geral sob alegação de deficiência e que as crianças com deficiência não sejam excluídas do ensino primário gratuito e compulsório ou do ensino secundário, sob alegação de deficiência [...] (Nações Unidas, 2006 apud Brasil, 2008a).

Considerando que "sistema educacional geral" significa todos os sistemas de ensino brasileiros, o entendimento da Convenção é de que os alunos com deficiência não devem ser excluídos da escola regular. Portanto, em termos de legislação ocorreu uma grande conquista para esses estudantes, pois, além do reconhecimento do seu direito à educação em um sistema educacional inclusivo, o poder público está assumindo os custos do atendimento especializado complementar ou suplementar, e reconhecendo que, para garantir o direito à educação dessas pessoas, é necessário reconhecer o direito à diferença, como direito à equiparação de oportunidades para alcançar boas condições de desenvolvimento para todos.

É importante agregar a essa reflexão o conceito de direito público subjetivo, que "configura-se como um instrumento jurídico de controle da atuação do poder estatal, pois permite ao seu titular constranger judicialmente o Estado a executar o que deve" (Duarte, 2004, p. 113). Na CF/88, art. 208, há o reconhecimento explícito de que "o acesso ao ensino obrigatório e gratuito é direito público subjetivo" (Brasil, 1988, § $1^{\circ}$ ). Isso significa que o Estado, além de assegurar esse direito juridicamente, deve garantilo material e efetivamente, por meio da realização de políticas públicas. Portanto, a educação, como direito social, público e subjetivo, interessa tanto aos beneficiários diretos (alunos) quanto à coletividade, se pensarmos nos benefícios da escolaridade para a sociedade como um todo. Ou seja, é possível acionar o Estado para garantir o interesse individual em relação ao direito assegurado juridicamente, como de forma coletiva, exigindo o cumprimento e a implantação de políticas públicas (Duarte, 2004).

Para a eficácia das normas constitucionais é preciso que as pessoas tenham convicção de que a legislação deve ser cumprida, isto é, que tenham consciência social. É necessária também a formação de uma consciência sobre a responsabilidade social, pois nenhum direito deveria se aplicar pela força, mas somente pela conscientização da obrigatoriedade do cumprimento das disposições legais. Ou seja, é preciso que se tenha consciência jurídica (Ribeiro, 2007).

Nessa linha de pensamento, cabe ressaltar a importância de divulgar e criar espaços de discussão sobre os princípios éticos 
dos principais documentos normativos, para que a população brasileira adquira maior consciência jurídica e social, pois exigir o cumprimento do que está assegurado em lei requer conhecimento sobre os direitos e deveres e uma posição ética frente aos princípios que sustentam a concepção de direitos humanos.

Comparato (2004) afirma que o brasileiro valoriza a cordialidade e a afetividade e por isso não gosta da desigualdade expressa em lei. Para o autor, na cultura brasileira a desigualdade faz parte da mentalidade e dos costumes. Esse caldo de cultura, que o autor chama de "individualismo anárquico", seria uma herança de nossos colonizadores, algo peculiar dos povos ibéricos. 0 direito é respeitado, mas não é cumprido, como na época da colonização as ordenações do rei eram veneradas, mas não eram cumpridas. Segundo Comparato (2004), desde aquela época não havia confronto: "Sempre achamos que as coisas se resolvem com jeitinho. [...] A regra geral existe lá em cima, como uma espécie de dogma, que veneramos, mas não aplicamos. Queremos um tratamento personalizado, individualizado" (p. 73).

Outro aspecto extremamente importante, abordado por Comparato (2004), diz respeito ao fato de que direito implica exigibilidade, mas a tradição brasileira não é no sentido da exigência, mas da acomodação e dos favores. Portanto, para esse autor, é necessário investir em programas de educação para os direitos humanos, de modo a combater a grande doença brasileira que é a naturalização da desigualdade.

Nesse sentido, é importante destacar as contribuições de Araújo e Neme (2009), que enfatizam:

\footnotetext{
a ratificação da Convenção traz instrumento importante e muito forte para a implementação dos direitos das pessoas com deficiência. No entanto, a Convenção, sem uma fiscalização efetiva e atuação em nome de sua implementação, pouco significará para a realização dos direitos das pessoas com deficiência (p. 740).
}

\section{Três teses sobre a intransigência}

Uma contribuição importante para entendermos as dificuldades para efetivar o direito à educação é a teoria de Hirschman (1992), explicitada em seu livro A retórica da intransigência, o qual trata de três tipos de reação que ocorrem, tanto por parte de pessoas de direita quanto de esquerda, em relação aos movimentos que deram origem à Declaração Universal dos Direitos Humanos (1948). 
0 autor formulou três teses que explicam o discurso de reação às conquistas populares da época - são as teses da "perversidade", da "futilidade" e da "ameaça".

De acordo com a "tese da perversidade", qualquer ação proposital que vise à melhoria de qualquer aspecto da ordem econômica, social ou política só serve para exacerbar a situação que se deseja modificar. A "tese da futilidade" sustenta que as tentativas de transformação social serão sempre infrutíferas, de fachada, pois as estruturas "profundas" da sociedade permanecerão intactas. E a "tese da ameaça" parte do princípio de que a mudança proposta, ainda que desejável em si, acarreta custos ou consequências inaceitáveis em relação aos seus benefícios (Hirschman, 1992).

As teses propostas por Hirschman (1992) podem ser utilizadas também para analisar a reação das pessoas à prática da inclusão escolar. Encontramos hoje, entre profissionais da educação e familiares de pessoas com deficiência, vários discursos que expressam reações à prática da educação inclusiva, embora não exista uma oposição explícita às diretrizes que a sustentam. De modo geral, há um consenso em relação à necessidade de respeitarmos e convivermos com as diferenças.

No dia a dia, é frequente ouvirmos argumentações no sentido de que a inclusão dos alunos com deficiência piora ainda mais a qualidade do ensino, e só será viável quando as escolas e os professores estiverem preparados. Esse tipo de retórica reconhece a mudança como desejável, mas a inviabiliza em razão de tantos riscos, dificuldades e consequências negativas, o que remete a pensar na "tese da ameaça", proposta por Hirschman (1992). Há também pessoas que argumentam sobre os riscos da inclusão escolar servir para reforçar os preconceitos e a situação de exclusão, o que tem relação com a "tese da perversidade". E ainda há outras que consideram a inclusão escolar de todos os alunos como uma utopia, já que a nossa sociedade é marcada por uma lógica de exclusão e desigualdade. Argumentos como esses podem ser analisados à luz da "tese da futilidade", na medida em que há uma descrença na possibilidade de uma mudança de mentalidade e de relações de poder, o que torna "futilidade" os esforços no sentido da inclusão escolar.

Qualquer processo de mudança gera reações de todo tipo e não poderia ser diferente no caso da educação. Fazer mudanças no âmbito da educação requer o diálogo e o respeito pelas diferenças, para que seja possível encontrar os pontos em 
comum, estabelecendo relações humanas pautadas em uma nova ética, que valoriza o potencial de cada um e busca o aprimoramento humano.

A efetivação de uma educação para todos com qualidade requer uma mudança de mentalidade na sociedade como um todo, e a construção de outros valores e outras relações de poder. A educação, com certeza, pode contribuir para essa mudança, mas certamente não será apenas pela educação que conseguiremos transformar a realidade atual de exclusão e desigualdade. São necessárias mudanças estruturais, em vários âmbitos, não apenas nas escolas.

É premente a realização de um amplo debate envolvendo toda a sociedade a respeito da educação que queremos oferecer às novas gerações. Temos uma estrutura e um funcionamento do sistema de ensino historicamente excludentes e realizar mudanças nessa realidade depende de transformações que devem ocorrer não apenas no âmbito das escolas, mas da sociedade como um todo. Dialogar, respeitar, e conviver com as diferenças não é uma questão de querer ou não. É condição necessária para uma mudança significativa no modelo de sociedade atual. Só assim conseguiremos garantir, de fato, o direito à educação para todos.

\section{REFERÊNCIAS}

ABENHAIM, E. Os caminhos da inclusão: breve histórico. In: MACHADO, Adriana Marcondes et al. Educação inclusiva: direitos humanos na escola. 10. ed. São Paulo: Casa do Psicólogo, 2005.

ARAÚJO, L. A. D.; NEME, E. F. Proteção das pessoas com deficiência. In: NUNES JUNIOR, Vidal Serrano (org.). Manual de direitos difusos. São Paulo: Editora Verbatim, 2009.

BENEVIDES, M. V. Cidadania e direitos humanos. In: CARVALHO, José Sérgio (Org.). Educação, cidadania e direitos humanos. Petrópolis, RJ: Vozes, 2004.

BRASIL. Constituição (1824). Constituição Política do Império do Brasil. Diário Oficial da União, Rio de Janeiro, 25 de março de 1824. Disponível em: <http://www.presidencia.gov.br/legislacao>. Acesso em: 18 jul. 2007. 
. Constituição (1934). Constituição da República dos Estados Unidos do Brasil. Diário Oficial da União, Rio de Janeiro, 16 jul. 1934. Disponível em: <http://www.presidencia.gov.br/legislacao>. Acesso em: 18 jul. 2007.

\section{- Constituição (1988). Constituição da República Federativa} do Brasil de 1988. Diário Oficial da União, Brasília, DF: Presidência da República, 1988. Disponível em: <http://www.planalto.gov.br/ ccivil_03/Constituicao/Constituiçao.htm>. Acesso em: 18 jul. 2007.

Lei no 9.394, de 20 de dezembro de 1996. Estabelece as Diretrizes e Bases da Educação Nacional. Diário Oficial da União, Brasília, 1996. Disponível em: <http://portal.mec.gov.br>. Acesso em: 20 jul. 2007.

Resolução CEB/CNE n² 2, de 11 de setembro de 2001. Institui Diretrizes Nacionais para a Educação Especial na Educação Básica. Diário Oficial da União, Brasília, 2001. Disponível em: <http://portal.mec.gov. br>. Acesso em: 20 jul. 2007.

Ministério Público Federal. 0 acesso de alunos com deficiência às escolas e classes comuns da rede regular. Brasília: Procuradoria Federal dos Direitos do Cidadão, 2004.

A convenção sobre os direitos das pessoas com deficiência comentada. Brasília: Secretaria Especial dos Direitos Humanos/ Coordenadoria Nacional para Integração da Pessoa Portadora de Deficiência, 2008a. Disponível em: <http://portal.mj.gov.br/corde/ arquivos/pdf/A\%20Convenção\%20sobre\%20os\%20Direitos\%20 das \%20Pessoas\%20com\%20Deficiência\%20Comentada.pdf>. Acesso em: 6 fev. 2010.

Ministério da Educação. Secretaria de Educação Especial. Política nacional de educação especial na perspectiva da educação inclusiva. Brasília, DF: Ministério da Educação, 2008b. (Não paginado). Disponível em: <http://portal.mec.gov.br/seesp/arquivos/pdf/politica. pdf>. Acesso em: 25 jan. 2010.

Decreto no 6.571, de 17 de setembro de 2008. Dispõe sobre o Atendimento Educacional Especializado, regulamenta o parágrafo único do art. 60 da Lei no 9.394, de 20 de dezembro de 1996, e acrescenta dispositivo ao Decreto no 6.253, de 13 de novembro de 2007. Diário Oficial da União, Brasília, 2008c. Disponível em: <http://www.planalto. gov.br/ccivil_03/_Ato2007-2010/2008/Decreto/D6571.htm>. Acesso em: 06 jan. 2009. 
Ministério do Planejamento, Orçamento e Gestão. Instituto Brasileiro de Geografia e Estatística. Síntese dos indicadores sociais 2008. Disponível em: <http://www.ibge.gov.br/home/presidencia/ noticias/noticia_visualiza.php?id_noticia $=1233 \& i d \_p a g i n a=1>$. Acesso em: 16 fev. 2009a.

Parecer CEB/CNE no 13, de 24 de setembro de 2009. Diretrizes Operacionais para o atendimento educacional especializado na Educação Básica, modalidade Educação Especial. Diário Oficial da União, Brasília, 2009b. Disponível em: <http://portal.mec.gov.br/dmdocuments/ pceb013_09_homolog.pdf>. Acesso em: 25 jan. 2010.

COMPARATO, F. K. A afirmação histórica dos direitos humanos. $2^{\text {a }}$ ed. rev. e ampl. São Paulo: Saraiva, 2001.

O princípio da igualdade e a escola. In: CARVALHO, José Sérgio (org.). Educação, cidadania e direitos humanos. Petrópolis, RJ: Vozes, 2004.

DALLARI, D. A. Um breve histórico dos direitos humanos. In: CARVALHO, José Sergio (org.). Educação, cidadania e direitos humanos. $2^{\text {a }}$ ed. Petrópolis, RJ: Vozes, 2004.

DUARTE, C. S. Direito público subjetivo e políticas educacionais. São Paulo Perspectiva, São Paulo, v. 18, n. 2, jun. 2004. Disponível em: <http://www.scielo.br/scielo.php?script=sci_arttext\&pid=S0102$88392001000200012 \&$ Ing $>$. Acesso em: 25 jan. 2010.

FÁVERO, E. O Direito a uma educação inclusiva. In: GUGEL, Maria Aparecida; COSTA FILHO, Waldir Macieira da; RIBEIRO, Lauro Luiz Gomes. Deficiência no Brasil: uma abordagem integral dos direitos das pessoas com deficiência. Florianópolis: Obra Jurídica, 2007.

GLAT, R.; BLANCO, L. Educação especial no contexto de uma educação inclusiva. In: GLAT, Rosana (org). Educação Inclusiva: cultura e cotidiano escolar. Rio de Janeiro: 7 Letras, 2007.

HIRSCHMAN, A. A retórica da intransigência: perversidade, futilidade, ameaça. São Paulo: Companhia da Letras, 1992.

Inclusion International. Mejor educación para todos: cuando se nos incluya también. Salamanca, ESP: Instituto Universitario de integración en La comunidad (INICO) da Universidad de Salamanca, 2009.

JANNUZZI, G. A educação do deficiente no Brasil: dos primórdios ao início do século XXI. $2^{a}$ ed. Campinas, SP: Autores Associados, 2006. 
MAIA NETO, Furtado, C. Cláusula pétrea e direitos humanos: verdades, conceitos e definições à luz da Constituição Federal brasileira. Disponível em: <http://www.uj.com.br/publicacoes/doutrinas/4955/Clausula_ Petrea_e_Direitos_Humanos___Verdades_Conceitos_e_Definicoes_a_ Luz_da_Constituica__FederaL_Brasileira>. Acesso em: 13 fev. 2010.

MAZZOTTA, M. Educação especial no Brasil: história e políticas públicas. 5. ed. São Paulo: Cortez, 2005.

MENDES, E. G. A radicalização do debate sobre inclusão escolar no Brasil. Revista Brasileira de Educação, Rio de Janeiro, v. 11, n. 33, dez. 2006. Disponível em: <http://www.scielo.br/pdf/rbedu/v11n33/a02v1133. pdf >. Acesso em: 25 jan. 2010.

MONTEIRO, A. R. O pão do direito à educação... Revista Educação e Sociedade, v. 24, n. 84, p. 763-789, set. 2003. ISSN 0101-7330.

OLIVEIRA, R. P. O direito à educação. In: OLIVEIRA, Romualdo Portela de; ADRIÃO, Thereza (orgs.). Gestão, financiamento e direito à educação. 3. ed. São Paulo: Xamã, 2007.

PONTES, P. A. G. Direito à educação. In: GUGEL, Maria Aparecida; COSTA FILHO, Waldir Macieira da; RIBEIRO, Lauro Luiz Gomes. Deficiência no Brasil: uma abordagem integral dos direitos das pessoas com deficiência. Florianópolis: Obra Jurídica, 2007.

RIBEIRO, L. L. G. O direito à igualdade, à dignidade da pessoa humana com deficiência e à autonomia. In: GUGEL, Maria Aparecida; COSTA FILHO, Waldir Macieira da; RIBEIRO, Lauro Luiz Gomes. Deficiência no Brasil: uma abordagem integral dos direitos das pessoas com deficiência. Florianópolis: Obra Jurídica, 2007.

TAVARES, D. A. Efetivação do direito ao ensino fundamental: uma questão de justiça. 2006. Dissertação (Mestrado) - Pontifícia Universidade Católica de Minas Gerais, Belo Horizonte, 2006. Disponível em: <http:// www.biblioteca.pucminas.br/teses/Direito_TavaresDA_1.pdf>. Acesso em: 06 jul. 2008.

TORRES, R. M. Educação para todos: a tarefa por fazer. Porto Alegre: Artmed, 2001. 